\title{
Editorial
}

\section{The Postgraduate Medical Journal in 1995}

1995 marks the 70th birthday of the Postgraduate Medical Journal, which first saw the light of day under its present title in October 1925.

Looking to the future, however, the January 1995 issue will herald major changes. The immediate and obvious one is that it will look different. Though retaining its familiar red cover, the Journal is becoming the more currently favoured A4 in size and will show the contents in full-frontal fashion, rather than modestly on the back cover as at present. We also have plans with our new publisher, BMJ Publishing Group, for a more readerfriendly layout that the A4 format will make easier to achieve.

We have also laid plans for a more structured programme of continuing as well as postgraduate medical education in both areas of which the
Journal and the Fellowship of Postgraduate Medicine played an important pioneering role in the UK, but these matters will be essentially in hands of the new Editor and the Editorial Board.

After 15 years as Editor and 6 years before that as assistant editor to the late Dr Ian Gilliland and subsequently Professor Donald Barltrop, the time has come for me to step aside. Our new Editor is Dr Charles R.K. Hind, M.D., F.R.C.P., Consultant Physician in General and Respiratory Medicine to the Royal Liverpool University Hospital and The Cardiothoracic Centre, Liverpool, and Lecturer in Medicine to the University of Liverpool. I wish Dr Hind and the Journal well in the years to come.

B.I. Hoffbrand, D.M., F.R.C.P. 